\title{
GEOLOGIC AND OCEANOGRAPHIC DATA DETERMINING THE "OLD FORESHORE ZONE", OF THE HERAKLION COASTAL AREA, CRETE ISLAND
}

K.G. PEHLIVANOGLOU*

A. PAPATHANASOGLOU
"The Greek Ombudsman, Independent Authority", Quality of Life Department,

5, Hatzigianni Mexi, 11528, Athens

* to whom all correspondence should be addressed:

\author{
e-mail: kpehli@synigoros.gr
}

Received: $13 / 5 / 2004$

Accepted: 23/11/2004

\begin{abstract}
Geologic, oceanographic and topographic data and field measurements, of the coastal area in front of Heraklion City, Crete Island, as well as deep sea wave measurements and shallow wave prediction numerical modelling were used for the determination of the 1884 foreshore. Data from numerous drills performed in the coastal area of Heraklion City used for the stratigraphic study of the area. For the calculation of the shallow area wave height, the deep area wave height and wind measurements in the of Cretan Sea were used, as input data of the shallow wave prediction model, taking into account the archive data about the sea bottom bathymetry and the topography of Heraklion area. Then, the maximum wave run up on the coastal area in 1884, which determines the limit of the old foreshore zone was calculated, and the critical requirements of the Act 2971/2001 and the Compulsory Law $2344 / 1940$ "the bigger however unexceptional sea wave run up" were estimated. Finally the innermost limit of the foreshore zone during 1884 was defined, as the $3.5 \mathrm{~m}$ level.
\end{abstract}

KEYWORDS: old foreshore, wave height, wave run-up, coastal stratigraphy

\section{INTRODUCTION}

According to the Greek legislation, if the actual innermost limit of the maximum wave run up differs from that observed in the past, it is called "old foreshore".

The Greek legislation requires the determination of the boundary of the old foreshore zone on the basis of its location in 1884. Present day and historic analysis of geomorphologic and stratigraphic data of the upper coastal layers of the area, as well as the wind and the wave field in the deeper and the shallower sea area, combined with data from mathematical simulation models for the significant wave height and the wave run up prediction on the coastal area, allow the accurate determination of the old foreshore zone.
The legislative framework defines the old foreshore zone as a public property and its mode of protection. Also the Supreme Administrative Court standard case law and its specialized decisions, accomplish the general legislative framework, defining the jurisdiction of the public authorities, the data which are compulsory to be taken into account, the procedures that that must be followed etc.

The legislative framework as well as the case law of the Supreme Administrative Court, defines the meaning of the basic terms (present foreshore, old foreshore, beach, etc), the framework of the procedure (autopsy, expertise etc), the acceptable methodology (study of aerial photographs and drill sections, maps, topographic diagrams etc), and the type of the data (geomorphologic, 
oceanographic etc), which the authorities should use in order to determine the old foreshore zone.

The previous mentioned scientific data can help the local authorized committees to identify the possible former coastal background and geomorphology of the area, the extension of the vegetation, the relief, the quality and the texture of the coast, the wave run up on the coast, the possible human intervention, etc.

Therefore, these committees must decide on the method, which must be applied for each case of the foreshore zones' determination.

The scientific background of the procedure for determining the old foreshore is the aim of the legislator, in order to protect the public property, the communal use of this area and the private properties as well.

Following the aforementioned rationale the aim of this work is to present:

The former and the recent legislative framework as well as the case law of the Supreme Administrative Court regarding the old foreshore zone and,

a) The way that available scientific data, such as geologic and oceanographic field data as well as any archive topographic and hydrographic data derived from charts, diagrams etc, can be utilized for the determination of the coastal area relief, paleotopography and paleogeography.

b) The numerical methods, such as significant wave height and maximum wave run up prediction model results, which can simulate the wave field and the wave run up conditions on the coastal zone during the critical date defined by the legislative framework.

Scientific data can provide the public authorities with sufficient information regarding the delimitation of the old foreshore zone.

The Heraklion coastal area, Crete Island was a typical case for the application of the previous outlined legislation and methodology.

In the present study we have used:

1) The results of the interpretation of the data from drills obtained by various public services (the Ministry of Environment, Physical Planning and Public Works and the Institute of Geology and Mineral Research),

2) Significant wave height and wind direction, from continuous measurements of the Hellenic Centre's for Marine Research observation buoy,
3) Significant wave height and maximum wave run up calculated by numerical prediction models, and

4) The geomorphology of the coastal zone at the beginning of the $20^{\text {th }}$ century.

\section{Legislative framework and case law}

Compulsory Law 2344/1940, article 2 paragraph 3, defines that: "In the case that due to illuviations or other reasons it is clear that, at the time of the determination, the foreshore zone position is different than in the past, and according to the evidence of witnesses examined under oath by the committee, or with the aid of other various indications, it is possible the old position of the foreshore up to the year 1884 to be determined, the committee proceeds to the determination of the "old foreshore zone", engraving a blue line on the diagram.".

The recent Act 2971/2001, article 1 paragraph 3, does not differ from the former legislation in respect to the old foreshore ${ }^{1}$ regime specifying that: "...old foreshore zone is the land zone which derived from the shifting of the foreshore towards the sea, due to illuviations or constructions and it is defined by the modern foreshore limit and the limit of the older foreshore".

According to the aforementioned law 2971/2001, (article 5 paragr. 3), as well as to the former Compulsory Law 2344/1940, (article 2 paragr. 3 ), the authorized committee is responsible to determine the position of the old foreshore zone, that formed up to the year 1884. The position of the old foreshore zone is defined from land indications or other conclusive evidence, apart of the witness's evidence. In the event that legal private properties exist, the committee is obligated to investigate up to the year 1884 for the determination. Otherwise, there is not a time limit if there are no such private properties.

Therefore, according to both acts, the Compulsory Law 2344/1940 and the recent Law $2971 / 2001$, the year 1884 is critical for the determination of the old foreshore innermost limit.

According to the case law of the Supreme Administrative Court (decisions 1508/2003,

\footnotetext{
${ }^{1}$ The Law 2971/2001, "Foreshore, beach and other provisions", replaced the Compulsory Law 2344/1940. However the present study was based on the former legislative regime, in order to research the res of the old foreshore, considering that there are not serious modifications of the legislative provisions.
} 
3949/2001, 2952/1998, 1185/1996, 686/1996), "the legislator considering the consequences that the old foreshore determination had, on the status of the private properties created by consecutive owners in the past, indicated the year 1884 as reference date for the retrospective foreshore definition". So, if legal private land properties existed up to the year 1884, between the present and the old foreshore zone, the committee was obligated to refer to the status of the year 1884, for the specification of the position and the boundaries of the old foreshore zone. These private properties that exist since 1884 up to present, should be excluded from the old foreshore zone.

This time limit was specified in accordance with the Act 22.04/16-5-1926 regarding "The administrative abortion from the land properties of the Airborne Defense". According to this Act in combination with the more recent acts regarding the suspension of moratoria, civilians may be able to convince usucaption and exception a private property from old foreshore zone, in the case that a minimum thirty-year period of occupancy convinced since 1884 up to date.

In contrast with former legislation, according to the recent act 2971/2001 (article 5, paragraph 3) the witnesses' evidence are excluded from the conclusive evidence, which could be taken into account for the determination of the old foreshore. As stated in the article 6 of this Law, only natural landmarks, aerial photographs, geological studies, as well as maps and past topographic diagrams may comprise acceptable evidence. The characterization of individual testimonies as non-evidence toward the definition of the foreshore, assures the safety of legal procedures by excluding evidence of doubtful reliability.

Therefore, proportionally to the procedure for the definition of the modern foreshore, the committees are obliged to base their decisions on strictly scientific criteria, but with date reference to the year 1884 or even earlier. The Supreme Administrative Court (3944/1998) stated as well that the recent and updated studies and data, should be taken into consideration for the determination of the old foreshore, so that the judgments to be based on recent data, increasing their validity.

Doris, (1995) suggests that for the determination of the "old foreshore zone" all the available data should be taken under consideration, such as aerial photographs, signs of debris, the state of the coast etc.

The old foreshore represents a public property, as the modern foreshore and the beach, it is however governed by a different legislative framework, (Consultatory Response 165/2000, 436/2001 First Instance Court of Heraklion, 5448/1996 Supreme Administrative Court), because it is not a public use area, and belongs to the private property of the state (Act 2971/2001 art. 2 par. 5). Especially, according to the Supreme Administrative Court (5448/1996) “...In case of illuviation, due to natural reasons or human acts, the area formerly occupied by the foreshore and the sea, being therefore a public use area, continues belonging to the state but passes as private property" Consequently, the general provisions concerning the public properties (Compulsory Law 263/1968, art. 2) do not govern the expulsion from the old foreshore.

Provisions that were established by the recent Act 2971/2001 (decision 1708/1998 Supreme Administrative Court - in accordance with article 24 of Compulsory Law 2344/1940), about the demolition protocols for the illegal constructions on the old foreshore are not applied, since these provisions are solely related to the modern foreshore and the beach. Therefore, the general provisions regarding the public properties are applied for the demolition of any illegal construction, located on the old foreshore, as derived from the aforementioned legislation.

Due to the non-public use of the old foreshore, this is a weaker protection compared to the other public properties, (e.g. the modern foreshore and the beach), because it belongs to the private property of the state. The most significant consequence of the incorporation of this zone in the private property of the state, is related to its more convenient management and disposition from the public administration, compared to other types of public properties. Nevertheless, regardless of the specific legislative status of the old foreshore, the modern foreshore and the beach, they continue to constitute a particularly sensitive ecosystem, which should be protected from damaging interventions. Consequently, both the old and the modern foreshore and the beach, require similar protection, as far as they are parts of the same unique and inseparable ecosystem. Their administrative separation must not affect the general planning of their livable management.

According to the aforementioned legislation, the innermost limit of the "old foreshore zone" can 


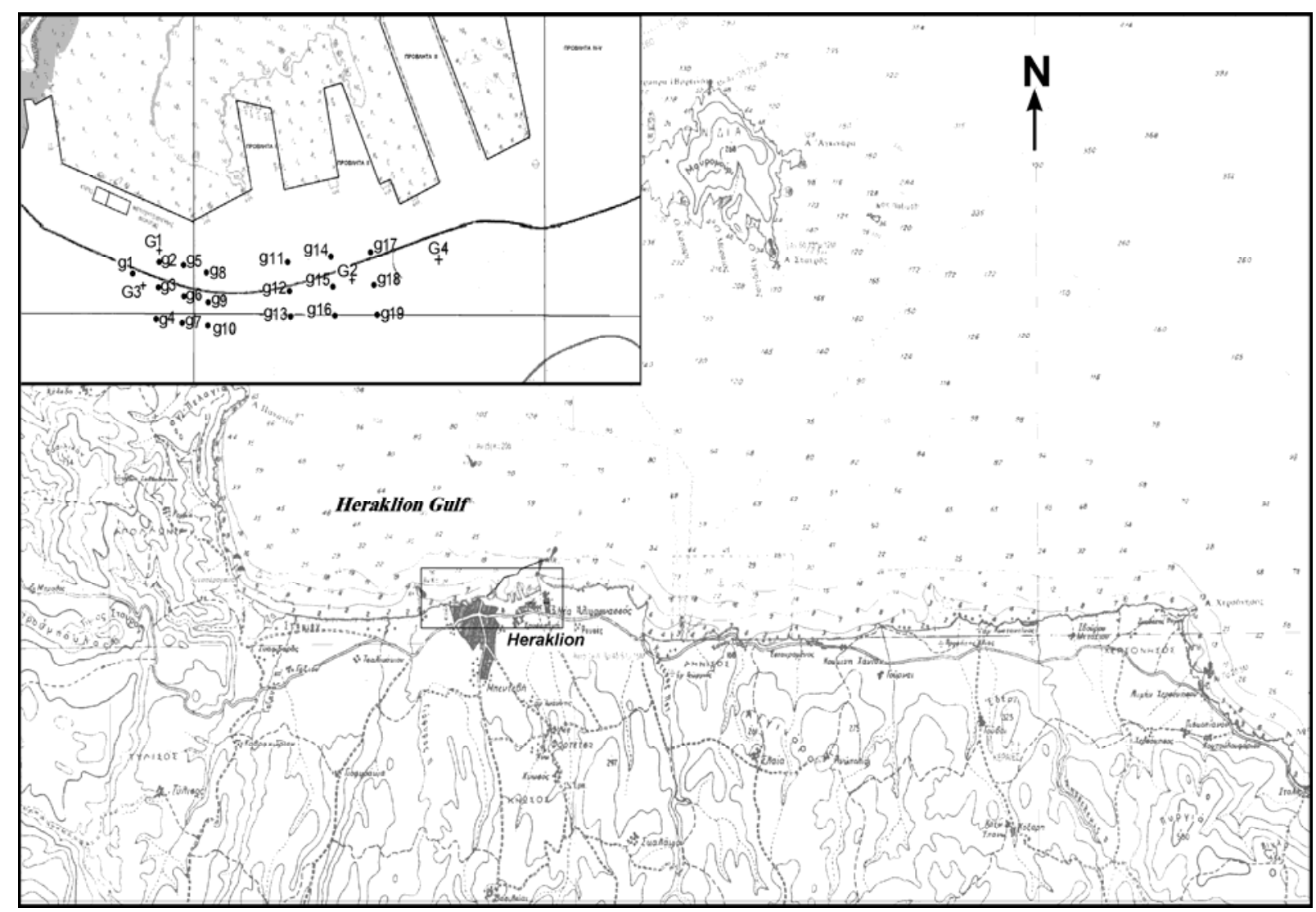

Figure 1. Geographic setting of the study area. (Background: Bathymetric charts 443 and 443/1, Hydrographic Service Hellenic Navy, 1998; 2002). Indicative drills' position performed by $(\bullet$ Ministry of Environment, Physical Planning and Public Works and (+) Institute of Geology and Mineral Reshearch.

be defined by the innermost limit of the foreshore zone of the year 1884. Therefore this limit can be defined similarly to the modern foreshore, as "the zone wetted by the bigger however unexceptional sea wave run up", but with a date reference to the year 1884. The term "bigger however unexceptional sea wave run up" denotes wave run up, which happened at least annually under extreme weather conditions. The determination of the old foreshore is closely related to the determination of the modern foreshore from the public authorities, according to the Supreme Administrative Court, (decision 2663/1985). Consequently, any cessation of the procedure for the determination of the modern foreshore, involves the cessation of the respective determination of the old foreshore, According to Supreme Administrative Court, (Department D' 2664/1985), "The cessation of the prefectorial decision for the determination of the foreshore zone, results to the cessation of the act which includes the part that defines the old foreshore as well”.

\section{Geology - Physical Setting of the area}

The wider region of Heraklion gulf, Crete Island that is examined in the present study, is a small part of the northern coast of Crete Island, (Figure 1). Presently, the morphology of the landward coastal region includes a section in front of the old city of Heraklion with intense relief, which presents alterations between small hills and small flat fields, up to the distance of 150-170 metres from the coastline. Eastwards of this section towards the $\mathrm{N}$. Alikarnasos area as well as landward, hills of a few tens of metres change to extensive flat field areas. Westwards of the Heraklion, towards the region Stomio Ammoudara the relief of the coastal area is smoother including an extensive sandy beach, due to the illuviations of the stream Giofiros that discharges in the area.

At around 1884, the same area had a soft relief. A part of the coastal land area was flat, with the exception of some small hills of few tens of metres height, towards the eastern limit and south of the present harbour. 


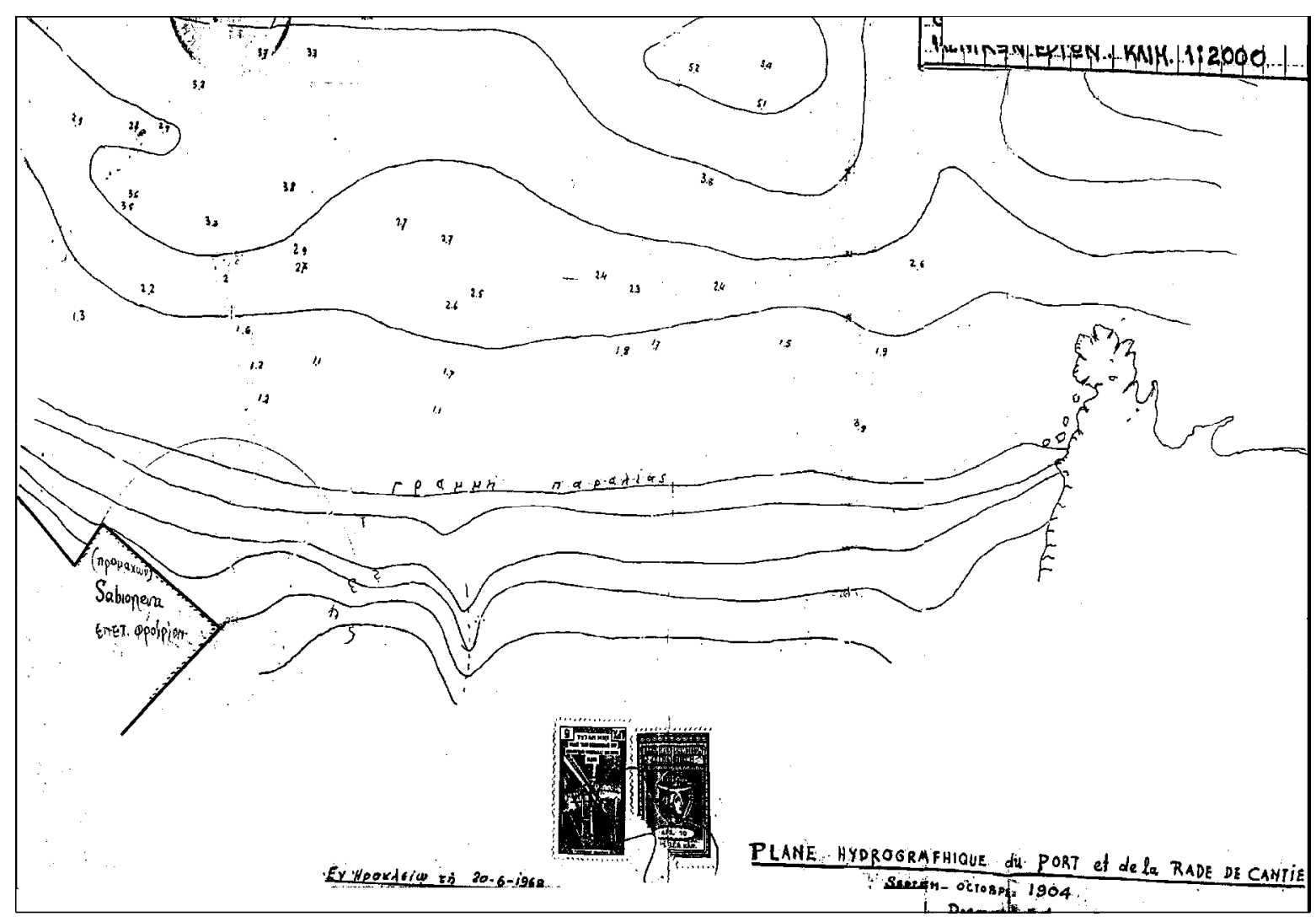

Figure 2. Extract of the hydrographic chart of the Heraklion coastal area (Alfred Diemer-Edouard Quellennec, 1904), (Original Scale 1:2000).

According to the archive charts and diagrams: a) "Plane hydrographic du port et de la rade de Cantie", (1904), (Figure 2), and b) "Diagram of the region of new port Heraklion", (Heraklion Port Authority, 1914), which were made for the preliminary study of the harbour construction, the coastal area before the works started, extended in altitude up to 3.5 metres and in distance of 20 - 50 metres from the coastline, in front of the "Sabbionara" area and the northern wall.

A small rise of 10 metres formed eastward of that beach and a small stream, supplied terrestrial material to the coastal area. East of the stream, the coastal area had a smoother relief; it extended in distance of 60 - 80 metres from the coastline, while landwards to the south small hills up to 25 - 30 metres height existed. This geomorphologic setting supported a smooth gradient of the landward coastal zone, which varied between $7 \%$ in the western up to $4 \%$ in eastern part.

In contrast to the landward coastal area, the underwater shallow seabed had a smoother relief and a smaller inclination towards the eastern and mainly to the western limit of the coastal area (Figures 1 and 2). A geological map of the Institute of Geological and Mineral Research (IGMR), suggests that Quaternary and Neogene formations, as well as alluvial deposits prevail in the wider area. Debris mainly covers the coastal area formations in front of the old city of Heraklion.

The Neogene formations on the eastern part of the study area consist of limestones, which altered to calcareous marls, or marly limestones. The formations in the central part of the area where the port of Heraklion was constructed consist of homogeneous marls, marly limestones and clays with plant or animal organic remains. The Quaternary formations consist of marine limestones, sandstones, conglomerates and marls in the western part, marine sandy terraces in the area of Heraklion harbour as well as fluvial deposits or enclosed basin deposits towards the eastern part close to the streambed of the Knossanos stream (Polyhronakis et al., 1999). The extensive nearly straight front of the coast, was unprotected from the north sector winds 
(northern, north-eastern and partly north-western winds) with the exception of a narrow sector of the coast behind the island Dia.

The fetch for wind wave estimation extends up to $75 \mathrm{n}$. m. to the north, $120 \mathrm{n}$. m. to the northeast and $150 \mathrm{n} . \mathrm{m}$. to the northwest directions.

Due to the extended fetch, the straight unprotected front of the coastline, the smooth gradient of the coast and the strong (6-7 Beaufort) or even stormy (8-9 Beaufort) winds of the Aegean Sea, which often blow in the area, the coastal zone was subject to the action of high waves, before the extensive protective works undertaken at the beginning of the $20^{\text {th }}$ century outside the old Heraklion harbour.

\section{METHODS}

In order to present the geomorphology of the coastal area, to identify the innermost limit of the wave run up and to calculate the effects of the wave height on the coasts before the harbour works were completed, oceanographic, geomorphologic and stratigraphic data were considered.

The following assumptions were made in order to apply the mathematical prediction models and calculate the oceanographic parameters:

1) The weather conditions, which affect the calculations for the prediction of the significant wave height and furthermore the maximum wave run up on the coastal area, should be assumed that did not change significantly on the Northern part of the Crete Island since 1884.

2) The available hydrographic and topographic charts and diagrams of that period can reproduce the geomorphology of the shallow underwater area and the topography of the coastal area.

From the same charts and diagrams, it is possible to calculate the gradient and reproduce the geomorphology of the coastal zone, previous to the beginning of the works dated in the year 1914, for the construction of the Heraklion harbour. The estimated gradient of the coastal area used as an input for the wave run up calculation. A small variation of the coastal area gradient, affects the calculation of the maximum wave run up and furthermore the innermost limit of the old foreshore zone.

\section{Oceanographic data}

The significant wave height very close to the coastline as well as the maximum wave run up on the coastal area, are the critical oceanographic parameters, which can outline and determine the innermost limit of the modern foreshore zone that can be affected by the sea. In the case of the data for the previous mentioned determination had a date reference to the year 1884, this innermost limit is the limit of the old foreshore zone.

Significant wave height and wind direction, derived, from continuous measurements of the Hellenic Centre's for Marine Research (HCMR, 2001) observation buoy, in the Cretan Sea, located at $35^{\circ} 37^{\prime} 12^{\prime \prime} \mathrm{N}, 25^{\circ} 38^{\prime} 24 " \mathrm{E}$, NE of the Heraklion were used. These data referred to a specific period during the winter of 2001, but according to the assumptions mentioned in the introductory section can be applied for the critical date 1884 as well. During that period of the winter 2001, extreme meteorological phenomena had been observed (strong NW winds), which produced high waves in the studied area.

The direct observations of the wave height projected in the nearshore zone on the basis of a standard diffraction model, by the HCMR which kindly provided these estimations. For the study of the wave field in the nearshore/shallow area, the SWAN (Holthuijsen et al., 1999) wave prediction model applied. It is a $3^{\text {rd }}$ generation wave prediction numerical model, which is based mainly on the equation of the wave action balance. The model accepts the following input data: a) wave parameters (the significant wave height, the average wave period and direction) and b) wind parameters (wind speed and direction). Also all the wave phenomena (shoaling, diffraction, reflection, and refraction) are fully modeled providing reliable description of the wave propagation for coastal areas, lakes and estuaries. The nearshore/coastal study area was defined, as it appears in Figure 3. The estimates of the wave heights provide the best available direct evidence of the significant wave height that affects the coastal area.

Finally, the previous mentioned nearshore wave height used as an input for the calculation of the maximum wave run up on the basis of the Mase (1989) prediction model. The maximum wave run up denotes the maximum level of the coast that should be affected by the waves under extreme weather conditions, which is the critical condition required by the Compulsory Law 2344/1940 and the Law 2971/2001: "the land zone that is affected by the bigger however unexceptional sea wave run up". 


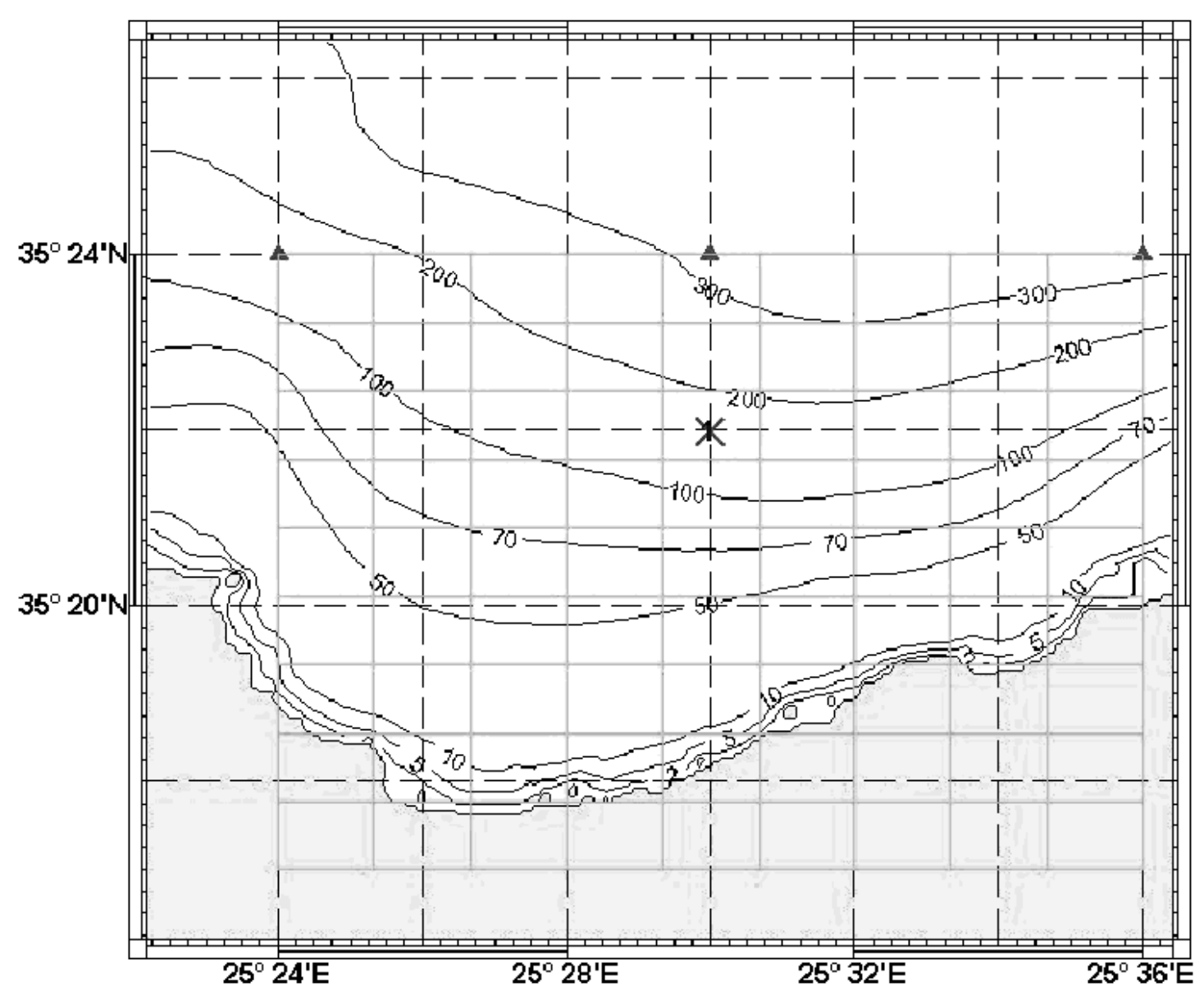

Figure 3. Indicative delineation of the simulation grid as well as of the shallow and the offshore area bathymetry.

\section{Geomorphologic and stratigraphic data.}

The stratigraphy of the upper layers of the coastal area, in combination with the available archive charts and diagrams describe the relief, the texture of the subsurface layers, as well as the evolution of the area during the previous century and the human intervention.

The stratigraphy of coastal area as well as the qualitative structure of individual subsurface layers was studied with the help of the drills performed by the Institute Geological and Mining Research (IGMR) in March and April 1999, and those of the Ministry of Environment, Physical Planning and Public Works in December 1967. The positions of the drills indicated on the topographic diagram of the area (Figure 4), (Koutsouveli, 1999, Polyhronakis et al., 1999), while the description of the layers were presented by Koutsouveli (1999) and Polyhronakis et al. (1999).
The aim of the drills was to recognise the presence of subsurface beds formed under former coastal area environment, as well as their texture and their buried depth. These beds denote sea action or former coastal or beach environment, indications of an old foreshore, actually covered by human intervention, confirming therefore the calculated maximum wave run up on the coastal area. The thickness of the debris (rubble, remains of constructions etc.) which denote human intervention, identified as well.

\section{DISCUSSION Geology - stratigraphy}

The study of the drills, that were performed in the central and western part of the coastal area of the Heraklion harbour (Figure 4), indicate that:

a) The surface layer, which expands from 1 to 4 metres depth, consists of debris indicating human intervention (rubble, remains of constructions etc.). The thickness of the 


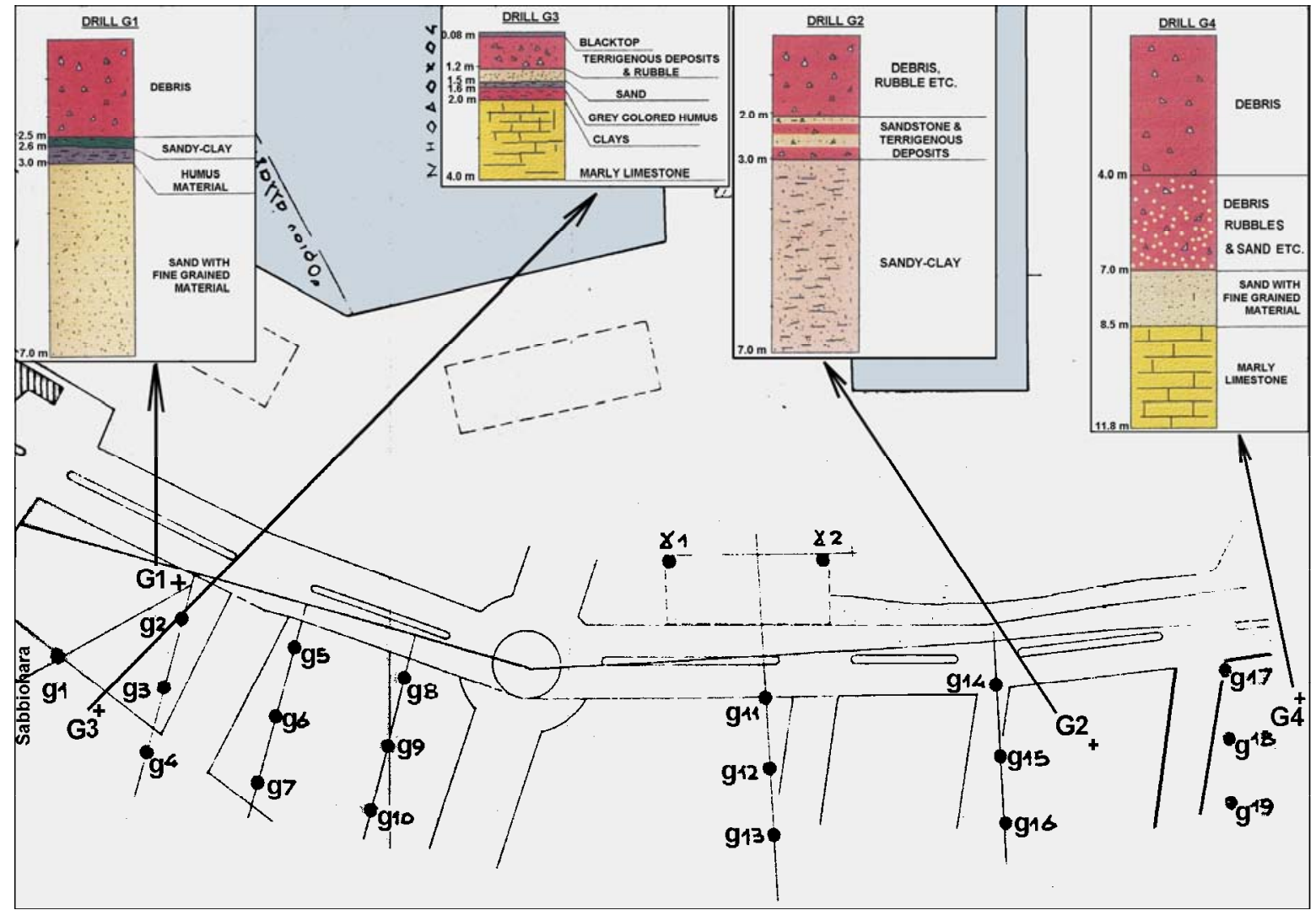

Figure 4. Indicative positions of the drills and geologic sections. (•) Ministry of Environment, Physical Planning and Public Works and (+) Institute of Geology and Mineral Research. (Topographic background: Heraklion city plan 1936, original scale: 1:1000)

debris is smaller in the landward and southern part of the area, closer to the "Sabbionara" (drilling G3) while their thickness increases considerably towards the northern part, closer to the coastline as well as in the north - western and western part of the area.

b) Under the aforementioned surface layer, a thin subsurface layer is recognised in some drills (G1, G3), 30 to $80 \mathrm{~cm}$ thick, where a mixed sandy humus material is observed. This layer is absent from drills G2 and G4.

c) In drill G1 that is closer to the coastline as well as in drill G2 in the central part of the area, under the aforementioned thin layer, material of marine origin exists. This extends to $7 \mathrm{~m}$ depth. The sandy or sandy-clay character of this material is similar to those of the coastal area material as well as to the marshy seabed materials. In contrast, in the southern drill closer to the Sabbionara (drill G3), under the aforementioned a thin subsurface layer of mixed material bedrock (marly limestone) observed.

d) In the eastern drilling G4, under the $4 \mathrm{~m}$ thick surface layer with debris, rubbles etc., appears a sandy layer mixed with pebbles, as well as separate layers consisting either of pebbles or sand. This structure denotes river action as well as intense transport of the material seaward. Under the aforementioned layers appears the solid bedrock in-depth of $8.5 \mathrm{~m}$.

The study of the drills that has been performed by the Ministry of Environment, Physical Planning and Public Works gives similar results. Among them the drills g1, g2, g3, g4, g5 and g6, (Figure 4), present a surface layer of debris and a subsurface fine sandy layer, 0.7 to $3.5 \mathrm{~m}$ thick. Moreover the drills g15, g16 and g17, which were made close to the small stream Knossanos, present a fine surface sandy layer, 1.5 to $3 \mathrm{~m}$ thick, with solid bedrock beneath the layer

Nevertheless some differences, regarding the thin subsurface layer, between the results of the drills 
Table 1. Boundary conditions that were applied on the limits of the simulation grid

\begin{tabular}{|c|c|c|c|c|}
\hline $\mathbf{H}_{\mathbf{s}}$ & $\mathbf{T}_{\mathbf{m}}$ & $\boldsymbol{\Theta}_{\mathbf{w}}$ & $\mathbf{u}_{\mathbf{w}}$ & $\boldsymbol{\theta}_{\mathbf{w}}$ \\
\hline 4.7 & 7.0 & 50 & 15.5 & 47 \\
\hline
\end{tabular}

of the Ministry of Environment, Physical Planning and Public Works and those of the drills of the Institute of Geology and Mineral Research, exist. The subsurface layer, of mixed sandy - humus material, which denotes alternate deposition of terrestrial and marine environment, either did not exist in the drills of the Ministry of Environment, Physical Planning and Public Works or was not evaluated due to its small thickness.

\section{Wave - wind conditions}

Combining the observed in 2001 wave heights with the oldest available bathymetry of the region (Figures 2 and 3) allowed for the estimation of the significant wave height nearshore. Consequently, it became possible to apply the mathematic simulation model for the critical chronological period, which stated by the legislation.

A time period during November 2001, when NW winds of $15-\mathrm{m} / \mathrm{sec}$ speed (7 Beaufort) prevailed, was selected for the calculation of wave in the nearshore/coastal area.

The statistic data sheet of the National Meteorological Service, Heraklion station, for the time period 1955-1987, states that, the annual frequency of the north sector winds (north-east, north, north-west) of 7 Beaufort or even bigger, is $0,6 \%$. This frequency corresponds to a total duration of 2-3 days (48-72 hours) per year when 7 Beaufort or even more prevail in the area. For the case of the specific study area we consider that, this annual frequency of the stormy winds and the wave field produced, as fulfilling the condition, which does the Act 2971/2001 define, "bigger however unexceptional sea wave run up".

During this time period, of November 2001, the significant wave height in the position of measurement (Cretan Sea, NE of Heraklion city), reached $4.8 \mathrm{~m}$ with a respective average wave period $7 \mathrm{sec}$, wave direction of $49^{\circ}$, and $15 \mathrm{~m} / \mathrm{sec}$ (7 Beaufort) wind speed. The previous mentioned wind - wave parameters suggests that the maximum wave height was greater than $5 \mathrm{~m}$ with a respective maximum wave period $9.3 \mathrm{sec}$ (H.C.M.R., 2001).
Accepting that the wind speed in the area exceeds the $15 \mathrm{~m} / \mathrm{sec}$ (29 Knots) 7 Beaufort), even with smaller frequency, $(0,132 \%$ per year, according to the statistic data of National Meteorological Service, Heraklion station), then it is suggested that the significant wave height will exceed the $5.5-6.0 \mathrm{~m}$ in the location of the measurement.

The nearshore/coastal wave prediction model run with a $200 \mathrm{~m}$ resolution, and the boundary conditions of the Table 1, (input data), that applied on the limits of the simulation grid. $H s$ : is the significant wave height in metres, $T m$ : is the average wave period in seconds, $\Theta w$ : is the average wave direction in degrees, $u w$ : is the wind speed in $\mathrm{m} / \mathrm{s}$ and $\theta w$ : is the wind direction in degrees. The terms $\Theta w$ and $\theta w$ denote the direction from which the wave and the wind come. Also 0 degrees correspond in the north direction.

The application of the wave prediction model in the nearshore/shallow coastal area, close to the land resulted that: a) a $4.8 \mathrm{~m}$ significant wave height in the deep area, at the place of measurement, under a 7 Beaufort wind force, creates a significant wave height greater than 3 $\mathrm{m}$, close to the coastline, where the depth is less than 5 meters, b) in the coastal area and the beach, the significant wave height was expected not to exceed $3.2 \mathrm{~m}$.

Considering irregular waves normal to the coastline, according to Mase (1989), the maximum wave run up on the subaerial coast was estimated to $3.2 \mathrm{~m}$, while the mean value of the $1 / 3$ of the higher wave run up was estimated to $2.17 \mathrm{~m}$.

It is logical to deduce that wind force 8-9 Beaufort will create a 5,5-6,0 m significant wave height in deep area, as well as a $3.6-3.9 \mathrm{~m}$ maximum wave run up on the coastal zone.

\section{CONCLUSIONS}

Considering a) the measured and the predicted wave height in the deep and shallow area, b) the wind conditions which have not changed considerably during the last century, c) the coastal area stratigraphy and d) the coastal area relief, which was estimated from the older 
available hydrographic and topographic charts and diagrams we concluded that:

The coastal area presented a mild slope, varied between $4 \%$ and $7 \%$, while in the underwater beach the gradient was even gentler.

The area was influenced by high waves, which in the shallower/coastal area of the $5 \mathrm{~m}$ depth, exceeded $3 \mathrm{~m}$ height, under the force of 7 Beaufort wind. Under the force of 8 - 9 Beaufort winds, logically deduced that the wave height should be greater than $3 \mathrm{~m}$.

The range of the coastal sandy zone as resulted from the study of the available topographic diagrams was large. A part of the beach was created by the wave action, while another part by the aeolian transport of the sand. However the part of the coastal zone that was affected by the wave action (as this it is described in the aforementioned paragraph) had a range between 20 and 80 metres.

Despite the fact that the significant wave height, which affected the nearshore coastal area, was greater than $3 \mathrm{~m}$ under 7 Beaufort wind force, the maximum wave run up on the coast is considered not to exceed the $3.2 \mathrm{~m}$ level. Under the force of 8-9 Beaufort wind force, the maximum wave run up was expected not to exceed the $3.5 \mathrm{~m}$ level along the coastal zone, due to its extended range and the attenuation on the sandy surface.
The thickness of the materials, which deposited for the embankment of the area during the harbour construction, as the drills confirm it, supports the suggestion that the maximum level, which was possible to be reached by the wave action could not exceed the contour line of 3.5 $\mathrm{m}$, as it appeared on the topographic diagram of year 1914.

Consequently, the upper limit of the foreshore zone in 1884 ("old foreshore zone" according to the Compulsory Law 2344/1940 and the Law $2971 / 2001$ ), should be the $3.5 \mathrm{~m}$ level, as it is recognised on the oldest reliable topographic diagram, entitled "Diagram of the region of new port Heraklion", (Heraklion Port Authority, 1914) scale $1: 1000$, coming from the "Technical Study of the Heraklion city harbour construction, of the 1914".

\section{ACKNOWLEDGEMENTS}

The authors wishes to acknowledge the Hellenic Centre for Marine Research which kindly provided the wind, wave field data and the wave prediction model estimations for the nearshore area, as well as to colleagues Prof. Michael Tsimplis from the Southampton Oceanography Center and Dr Nikiforos Kypraios, Coastal Engineer, for their comments and corrections.

\section{REFERENCES}

Diemer A. and Quellennec E. (1904), Plane hydrographic du port et de la rade de Cantie. Scale 1:2000, Heraklion Port Authority.

Doris E. (1995), The Public properties. Shoreline, beach, marine environment pollution. Vol. B' Issue A', eds Sakkoulas, Athens.

Hellenic Center for Marine Research, (H.C.M.R.) (2001), Poseidon System Web site: http://www.poseidon.ncmr.gr, Institute of Oceanography, (dates of access 2/11/200124/11/2001).

Hellenic Navy Hydrographic Service (1998), Crete Island, East - Central Part, Chart No. 443. Scale 1:100000.

Hellenic Navy Hydrographic Service (2002), Heraklion Harbour (Crete Island), Chart No. 443/1. Scale 1:5000.

Heraklion Port Authority (1914), Diagram of the Region of New Port Heraklion, Scale 1:1000. "Technical Study of the Heraklion City harbour construction".

Holthuijsen L.H., Booij N., Ris R.C., Haagsma I.J.G., Kieftenburg A.T.M.M. and Kriezi E.E., (1999), SWAN Cycle III version 40.11, User manual, Electronic version, Delft University of Technology, p. 124, http://swan.ct.tudelft.nl, date of access 18/2/2004.

Koutsouveli An. (1999), Geologic study and determination of the old coastline in the land area of the Heraklion harbour, Crete. Unpublished technical report of I. G. M. R., Athens, p. 23.

Mase H. (1989), Random Wave Run up Height on Gentle Slopes, Journal of the Waterway, Port, Coastal and Ocean Engineering Division, 115, 649 - 461.

Polyhronakis A., Athanasoulis E. and Zourbakis B. (1999), Geological report on the research drills of Heraklion harbour land area. Unpublished report of I.G.M.R., Athens, p. 11. 